\title{
Distinguishing marine habitat classification concepts for ecological data management
}

\author{
Mark J. Costello* \\ Leigh Marine Laboratory, University of Auckland, Box 349, Warkworth, Northland 0941, New Zealand
}

\begin{abstract}
Including ecology in biodiversity data management systems requires classifications of habitat terms that provide standard definitions and indicate their relationships. In addition to databases, a wide range of intergovernmental, conservation and fishery organizations require classifications of habitats and ecosystems to enable comparisons between areas and organize information in maps and reports. However, all of the terms used to describe habitats are concepts whose definition is context-dependent. This paper reviews the key concepts and ecological perspectives involved in classifying marine 'habitats' and 'biotopes' (habitat plus its associated species) so as to advise how they may be used in data management systems. Classifications of biotopes provide practical measures of biodiversity at the ecosystem level. As an example the habitat of a benthic invertebrate is very different in spatial scale to that of a parasite, plankton, tuna or whale. Habitats can be geophysical and/or biogenic, and may operate at different spatial scales. For example, aggregations of deepsea coral colonies $<1 \mathrm{~m}$ in diameter may form $\mathrm{km}$-scale reefs which contain other habitats (e.g. sediments, sponges). An ecosystem can be physiographically defined as a lagoon, seamount, estuary, abyssal plain or entire ocean. Different sampling methods will define different regions, such as satellite images of ocean colour, acoustic maps of the seabed, in situ sampling of water or sediment cores and maps derived from analyses of species distributions that may define biogeographic regions. Because they are sampled (and thus defined) by different methods and can operate at different spatial scales, separate classifications are recommended for (1) nekton, plankton and benthos and (2) regions (defined to suit political, geographic or management areas), seascapes (defined by topography or water mass), biotopes and guilds (e.g. based on body size, diet or sampling method). Furthermore, it is recommended to record the measurable features used to describe biotopes (e.g. depth, dominant species, substratum) and to avoid imposing a classification hierarchy where the concepts and methods of defining them are different. Indeed, one can let users create the most parsimonious classification for their purposes.
\end{abstract}

KEY WORDS: Methods $\cdot$ Biogeography $\cdot$ Ocean $\cdot$ Biotope $\cdot$ Seascape $\cdot$ Eco-informatics $\cdot$ Biodiversity

\section{INTRODUCTION}

Habitat classifications are required for reporting, mapping and comparative analysis of ecological data. Since the early 19th century, they have been developed for local and regional surveys to help organise and describe the environment and associated assemblages of species in a consistent manner (e.g. Pérès \& Picard 1964, Connor et al. 2004, 2006, Valentine et al. 2005). Southern (1915) reviewed 14 publications since 1832 that distinguished marine habitats based on their characteristic species, their benthic or pelagic nature, intertidal zonation, substratum, salinity, wave action, depth and light penetration, and proposed a classification from the seashore to abyssal plain off the west coast of Ireland. Such classifications permit: habitats and marine resources (e.g. shellfish beds) to be mapped at different spatial scales to visualise their distribution and manage their harvest; ecosystem processes and services to be quantified in space and time; species to be grouped according to their habitat for ecological data analysis; and prediction of species 
occurrence from physical environmental data (e.g. Southern 1915, Zacharias et al. 1999, Costello et al. 1990, 1999, Costello 1992, Connor et al. 2004, Andrefouet et al. 2005, Costello \& Emblow 2005, Cattrijsse \& Hempel 2006, Redfern et al. 2006, Mumby et al. 2008). Different habitats will require different sampling methods, so habitat classifications also provide a basis for designing monitoring programmes to assess environmental quality (Diaz et al. 2004).

Environmental management and conservation requires standardised classifications and terminology for habitats to enable consistent mapping of the environment across all possible habitats. This aids ranking of areas for conservation management, such as in selecting locations for Marine Protected Areas (MPAs) so they are representative of the habitats of the country or region. In this instance, habitats are used as a surrogate for biodiversity because it is impractical to sample and map all species distributions in a region. However, as most ecological studies are local to regional in scale, the scope and structure of their classifications have been specific to their study areas.

The classification of biological species creates a phylogenetic hierarchy that represents a species' evolutionary history. In contrast, there is no common conceptual framework to provide a standard definition and classification of habitats, ecosystems and related concepts (Jax 2006). They are variously defined by features such as geography, topography, sediment grain size, nutrients, salinity, temperature and/or species composition. Thus, to develop a global classification that covers all marine biodiversity, benthic and pelagic, shallow and deep sea, at a variety of spatial scales, is challenging.

During this decade, an increasing amount of marine species distribution data has been published online (Costello \& Vanden Berghe 2006). For example, the Ocean Biogeographic Information System (OBIS) publishes about 19 million records of over 100000 species from 600 data sets (www.iobis.org, Costello et al. 2007). The Global Biodiversity Information Facility (GBIF) contains all the data from OBIS with similar mapping tools, plus additional data (http://data.gbif.org). One of the largest contributors to OBIS, OBIS-SEAMAP, enables exploration and analysis of marine mammal, bird and turtle distributions (Halpin et al. 2006, Best et al. 2007), while FishBase provides all kinds of information on fish (Froese \& Pauly 2009). Another OBIS contributor, Hexacorallia, provides a world database on sea anemones with tools for mapping species against environmental data (Guinotte et al. 2006), and AquaMaps provides predicted and editable species range maps (Kaschner et al. 2008). However, at present none of these resources has a habitat classification to place these species distribution data in an ecological context.
The Group on Earth Observations (GEO) is a partnership of over 80 countries that plan to create a Global Earth Observation System of Systems (GEOSS) that will require a method of classifying marine ecosystems (Andrefouet et al. 2008). However, to make these data ecologically relevant requires classifying the species or their locations according to their environment. Classifications derived from local studies may not be suitable for application to studies from other geographic areas and/or which used different sampling methods. Thus it has been unclear how globally applicable databases should classify their data ecologically. This paper describes the key concepts and considerations in designing marine habitat classifications, including a short review of terminology. It then outlines how such data can be organised using existing geographic classifications and how each datum could be labelled according to standard habitat descriptors.

\section{KEY CONCEPTS AND TERMINOLOGY}

The terms habitat, biodiversity, ecosystem and ecotone are concepts, and thus can only be defined in a certain context. This context depends upon the species of interest and the sampling methods, thus different methods will provide different definitions of each term.

\section{Habitats from perspectives of nekton, plankton and benthos}

It is generally agreed that a habitat is defined as the physical and chemical environment in which a species lives. Researchers considering free-swimming and wideranging animals such as birds, mammals, turtles and fish (nekton) are likely to have different perspectives on habitat than those studying plankton and benthos. These 3 different perspectives also involve completely different methods of observation and sampling. Furthermore, these species vary in their spatial distribution on very different time scales. Nekton may move significant distances within minutes, whereas plankton move little but within a moving water mass, and benthic fauna and flora may never move within their lifetime (O'Dor et al. 2009). Both the environmental conditions and spatial area will be different for these different biota. Thus to combine the 3 perspectives of nekton, plankton and benthos within a single habitat classification seems unnecessary and is potentially misleading about their relationships.

\section{Ecosystems}

Ecosystems are the combination of one or more habitats with communities of species that can be consid- 
ered a functional unit (Jax 2006). They are connected in their use of space, food or other resources at the same time, even though the ecosystem will exchange materials and individuals of its species with external ecosystems. Ecosystems are thus comprised of physical habitats, species and biogeochemical processes (e.g. nutrient cycles). Sometimes habitat and ecosystem are incorrectly defined as a geographic place where species live. However, both terms are normally applied to a set of physical environments that can occur repeatedly in space and time, such as estuarine ecosystems or seagrass beds. Thus they are recurrent ecological features. While the concept of ecosystem has heuristic value, it has been applied so loosely in the literature (Jax 2006) that it is thus difficult to standardise for data management purposes.

\section{Biodiversity and biotopes}

The Convention of Biological Diversity definition of biodiversity comprises 3 levels: (1) the population (genetic), (2) the community of species and (3) the ecosystem and its interactions (Costello 2001). Biodiversity is always measured by the use of surrogates because of the cost and practicality of recording all species in any place repeatedly. The question is thus how appropriate are the surrogates at the population, community and ecosystem levels of biodiversity? Whether the available data are representative of marine biodiversity is uncertain because they only include a small proportion of the known species in an area, usually the larger and more conspicuous species that are easier to sample and identify. Furthermore, the proportion of species known to science varies from 10 to $90 \%$ in different geographic areas and taxonomic groups (M. J. Costello unpubl. data). The use of semiquantitative data on the dominant species with a list of associated species in a defined physical habitat (i.e. mapping biotopes) provides practical measures of biodiversity at all 3 levels. Additional data on the community structure and ecosystem interactions can be reasonably inferred from these data. Thus classifications that include biotopes can be used as ecosystem-level measures of biodiversity.

\section{Ecotones}

Boundaries between habitats may be narrow or broad, and play important functional roles in ecosystems in terms of nutrient flow and dispersal corridors (Risser 1995). The seashore is such an ecotone (between land and sea), as is the reef edge (between reef and sediment habitats). Estuaries are ecotones between marine and freshwater environments and, like fronts between water masses, have high plankton biomass and productivity. Because these ecotones have uniquely different species abundances compared to adjacent habitats, I suggest that they are habitats and biotopes in their own right. At one level an ecotone is a boundary, but on closer examination it may contain several habitats within it. Thus for the purpose of this paper, ecotones are considered a useful concept to illustrate new habitats that arise from the interface between habitats. Whether they are presented as habitats or ecotones is likely to reflect the spatial scale of a study.

The IMCRA Technical Group (1998) discussed the presence of biotones, transition zones between biogeographic regions, and that they may be larger in area than some regions. While it is clear that there are major differences in species composition at geographic scales that are due to evolution over geological time scales, whether the regional biota change over boundaries or gradients is less clear (Southern 1915, van der Spoel 1994, Semina 1997). Thus the utility of biotones is less evident than that of ecotones.

\section{Methods of defining habitats: remote sensing, in situ sampling and expert opinion}

There are 3 general methods of mapping where habitats occur in the environment, namely remote sensing, in situ sampling and expert opinion (Table 1). Remotely sensed (satellite, aerial and acoustic) data provides different information at different spatial scales to in situ sampling (e.g. visual, gabs, cores, dredges, nets and traps) of the water column and seabed. The first may use satellites to map sea surface colour, and thus the distribution of phytoplankton biomass as chlorophyll across entire oceans. Satellite images and aerial photography can also be used to map shallow-water coral reefs, seagrass beds and probably other habitats (Andrefouet et al. 2008, Wright \& Heyman 2008). Satellite-derived gravitational anomaly data have been used to produce world bathymetries (Smith \& Sandwell 1997, Becker 2008, Becker et al. 2009) that could be used to identify large seabed features (M. J. Costello \& A. Cheung unpubl. data). Acoustic mapping has become the best way of providing terrain maps of the seabed at all depths (e.g. Legendre et al. 2002, Freitas et al. 2006, Wright \& Heyman 2008), and can be used to map tubeworm distributions (Degraer et al. 2008).

The various sampling methods, from satellites to acoustic, video and spot samples, are suitable at different spatial scales (Kenny et al. 2003, Diaz et al. 2004). However, knowing what species are present almost always requires in situ samples taken at point locations 
Table 1. Comparison of how 5 key concepts associated with marine habitats are defined and the sampling methods used to collect information about them

\begin{tabular}{|c|c|c|}
\hline Concept & Defined by & Sampling method \\
\hline Habitat & $\begin{array}{l}\text { Physical environment in which a species, or assemblage of species, } \\
\text { lives }\end{array}$ & $\begin{array}{l}\text { Dependent on the species of } \\
\text { interest }\end{array}$ \\
\hline Region & $\begin{array}{l}\text { Expert opinion based on biogeography, oceanography and practical } \\
\text { management area }\end{array}$ & $\begin{array}{l}\text { Only sampled as seascapes or } \\
\text { habitats }\end{array}$ \\
\hline Seascape & Topography, physiography and hydrography & $\begin{array}{l}\text { Acoustic mapping, aerial photo- } \\
\text { graphy, spectrophotometric sensing }\end{array}$ \\
\hline Biotope & Biological community and its physical habitat & $\begin{array}{l}\text { Visual observation, photography, } \\
\text { samples of substrata and biota }\end{array}$ \\
\hline Guild & Habitat, body size, sampling method (e.g. net or sieve mesh), diet, habit & As for biotopes \\
\hline
\end{tabular}

or along transects (Wright \& Heyman 2008). Whether recorded by scuba diver, video, photographs or identified in the laboratory from seabed or water samples, this data provides a more accurate report of the species-habitat relationship than remotely sensed methods. However, the latter enable extrapolation of the extent of the habitat and likely species distributions. In both these cases the habitat definition is based on verifiable physical and/or biological data. Where such data are not available, or a mixture of data is available, habitat maps may be drawn by experts based on their opinion of available data.

Using expert opinion has the advantage of rapidly producing maps based on individuals' knowledge at low cost. The fact that different experts will have different experiences and perceptions may be helpful, especially if this is brought together to produce a standardised methodology. The fact that leading scientists produced the consequent maps may be an advantage and result in their acceptance by the scientific community. However, this sidesteps a more objective approach based on empirical data, and it may conceal data gaps. If the experts' focus is on a map produced by consensus rather than a common methodology, then the outcome may be a mix of different weightings of physical or ecological data and/or socioeconomic and political considerations. This particularly applies to maps of biogeographic regions as discussed below.

\section{PRACTICAL CONCEPTS FOR HABITAT CLASSIFICATION}

\section{Four key concepts: regions, seascapes, biotopes and guilds}

The physical environment that is used to circumscribe a species' habitat can vary greatly depending on the ecological perspectives and methods used to define habitats. Thus 'regions' of the ocean may be mapped using management criteria and expert opinion, 'seascapes' by topographic (physiographic) features, 'biotopes' by the assemblage of species in a particular physical environment and ecological communities as 'guilds' (Table 1).

Regions

The boundaries of regions may be based on political history, physiographic features, depth zones and/or biogeographic knowledge. Recently, 3 biogeographic classifications have been proposed that collectively cover the epipelagic, coastal and deep-sea benthic environments: namely Longhurst (1998), Marine Ecosystems of the World (MEOW) (Spalding et al. 2007) and Global Open Oceans and Deep Sea (GOODS) (UNESCO 2009). While many scientific publications, from textbooks to journal articles, refer to biogeographic regions at oceanic to global scales, they provide very limited or no species data to support these regions. In some cases, their boundaries may be primarily based on geography and politics, with species distributions playing a minor role (Vinogradova 1997, Spalding et al. 2007). There is a danger that in using maps, readers may not appreciate the limited empirical support for such regions, and the intermingling of different types of information used to produce them. It may be better to think of maps derived from expert opinion alone as a hypothesis, and data-derived maps as models, of biogeographic regions.

The only global regions consistently based on a standard set of empirical data are those detailed in Longhurst (1998) for the open-ocean surface (epipelagic) waters. They provide the best estimate of ocean surface biogeographic regions for the world at present because they are based on environmental profile and ocean-colour satellite data as reasonable surrogates for phytoplankton biomass and ecosystem processes (Pauly 1999). While the Longhurst (1998) classification 
is the most objective global marine biogeographic classification, it only applies to the surface ocean, its inclusion of coastal (neritic) areas is limited and it remains to be tested against pelagic and benthic species distributions. Longhurst (1998) distinguished 4 pelagic biomes, namely westerlies (wind mixed, euphotic), trades (distant geostrophic forcing, e.g. by Coriolis effect), polar (brackish surface due to ice melt) and coastal (land runoff and tidal forcing). These were defined by the dominant vegetation (phytoplankton) in a comparable way to terrestrial biomes, and subsequently divided into provinces based on depth-profile sample data. However, extensive Russian phytoplankton data have indicated only 4 distinct assemblages, polar-boreal, tropical, Atlantic and Pacific (Semina 1997), although cosmopolitan, endemic and bipolar species occurred. Similarly, Russian zooplankton data indicated only 3 major biogeographic assemblages: Arctic-boreal, tropical and Antarctic (Vinogradov 1997). Their vertical distribution could be divided into surface (epiplankton), migratory (interzonal) and deep-sea groups for mesoplankton (includes copepods); and into epi-, meso-, bathy- and abyssal-pelagic assemblages for macroplankton. While physical conditions partly explain plankton distributions, nutrient limitation, shading, competition, grazing and predation appear to also influence their distribution as they do in benthic and terrestrial environments (Vinogradov 1997, Longhurst 1998).

Large Marine Ecosystems (LMEs) are a network of some 64 coastal areas selected due to their importance for resource management (Sherman et al. 2005). The MEOW classification is also coastal, and it encompasses LMEs, countries' Exclusive Economic Zones (EEZ) and earlier national regions such as bioregions and ecoregions. MEOW comprises 232 ecoregions grouped into 62 provinces and 12 realms. Because of their size and location, the biota of these regions are likely to reflect their evolutionary history and degree of endemicity, and thus may be considered biogeographic regions. However, using other geographical areas, such as national boundaries or seas, could also illustrate biogeography. GOODS was developed to fill the open ocean and deep-sea gaps in MEOW, and similarly was hypothesis- and expert opinion-driven due to the limited new species data available for analysis (UNESCO 2009). However, it builds on the reviews of bathyal, abyssal and hadal data by Zezina (1997) and Vinogradova (1997). Analyses of species distribution data are necessary to determine how equivalent MEOW, GOODS and other classifications of geographic areas are in terms of biogeography. It may be found that there are few or no distinct biogeographic boundaries in the oceans compared to the terrestrial environment (van der Spoel 1994).
While the classification of world terrestrial ecoregions was similarly grouped into biomes and realms, and benefited from the availability of vegetation cover data, it was also a compilation of existing biogeographic schemes rather than an analysis of species distribution data (Olson et al. 2001). Despite the better quality and quantity of data for terrestrial than marine environments, the same issues of variation in the density of remotely sensed and in situ data in space and time compromise the combining of data collected by different methods in different places, seasons and years (Benson 2008). Maps of classifications in both environments will benefit from greater transparency and repeatability of methodology so they can be repeated as new data emerge. Furthermore, biogeographic boundaries may change as species respond to climate change.

All of the above-mentioned classifications of regions recognise that their divisions warrant better substantiation by species distribution data. Looking forward, the publication of data used in biogeographic classifications should be mandatory and in open-access databases (e.g. GBIF) to allow the classification results to be reproduced and reanalysed when combined with new data (Costello 2009).

A physical classification of the oceans related to depth zones is widely used, and includes littoral, sublittoral, continental shelf, slope, rise, plain, bathyal, abyssal, hadal, epipelagic and mesopelagic (Table 2). However, definitions of the depth limits of these zones can vary (Vinogradov 1997); therefore, definitions based on species distributions, as used for coastal zonation (e.g. supralittoral, eulittoral and infralittoral), may be more useful. Within a region these may prove to be depth-related and thus practically defined by depth (A. Butler pers. comm.). Zones on rocky seashores are not defined in centimetres because it is well known that the limits of the zones vary with tidal range and wave exposure. The infralittoral zone is defined as the sublittoral area dominated by seaweeds, and its depth varies with water clarity. Similarly, it may be expected that the depth ranges of deeper sublittoral communities will vary according to light penetration, sea temperature and other factors in different parts of the oceans (Vinogradova 1997). In the absence of practical biological definitions of deepsea seabed communities (below infralittoral), it is recommended that offshore regions be classified simply as depth zones without inferring any biological significance. The epipelagic zone is oceanographically defined as the wind-mixed sunlit (euphotic) surface waters above a seasonal pycnocline, and its depth can vary from 30 to $200 \mathrm{~m}$ (Longhurst 1998). However, many texts classify it as the zone from the surface to $200 \mathrm{~m}$. A study of fish assemblages on cold-water 
Table 2. Examples of the concepts of regions, seascapes and biotopes (= habitat including biota)

\author{
Coastal (nearshore) \\ Regions \\ Countries' Exclusive Economic Zones (EEZ); Large Marine Ecosystems (LME); Marine Ecoregions of the World (MEOW); FAO \\ areas; ICES areas; seas and oceans (IHO) \\ Seascapes \\ Estuaries; inlets; lagoons; fjords; bays; straits, sounds; tidal rapids; headlands; platforms; banks, shoals, sandwaves; gullies, \\ channels, coral reef systems \\ Biotopes \\ Supralittoral rock lichen zones; barnacle Chthamalus on eulittoral wave-exposed rock; Ascophyllum seaweed on wave- \\ sheltered eulittoral rock; talitrid amphipods on sandy beach strandline; Corophium amphipods on intertidal mudflats; sea- \\ grass beds; Mytilus mussel beds on eulittoral rock; subtidal oyster beds; saltmarsh; maerl beds; mangrove forests; under-ice \\ communities

\section{Offshore} \\ Regions \\ FAO areas; ICES areas; seas and oceans (IHO); Global Open Ocean and Deep-Sea (GOODS) \\ Seascapes \\ Continental shelves; continental slopes; continental rise; shelf break; mid-ocean ridges; semounts, guyots; peaks, pinnacles; \\ hills, knolls; saddles; terraces; plateaus; basins, pockmarks; mud volcanoes; hydrothermal vents; cold seeps; whale falls; \\ aprons, fans; deep-sea trenches; troughs, valleys, deeps; submarine canyons; abyssal plains \\ Biotopes \\ Lophelia (coral) reefs \\ Pelagic \\ Regions \\ Longhurst's areas ${ }^{\mathrm{a}}$ \\ Seascapes \\ Water masses; gyres; upwelling; fronts; pycnoclines; thermoclines; sea surface; eddies

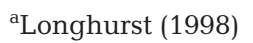

corals in the Northeast Atlantic found distinct coastal and deep-sea assemblages, but separated at 400 to $600 \mathrm{~m}$ depth, not $200 \mathrm{~m}$ (Costello et al. 2005). Further analysis of offshore zones may identify characteristic communities that provide biological definitions. The water column may be divided into nearshore (neritic, coastal) and offshore or oceanic water masses. As with depth zones, it is not possible to define these in kilometres, and biologically based definitions may be more valuable.

\section{Seascapes}

The term seascapes is used here to refer to underwater landscapes defined by their physiographic features. Alternative terms include marine landscapes, formations, geoforms, landforms, hydroforms, biogeomorphological units, geomorphic features and macrohabitats (Greene et al. 1999, Butler et al. 2001, Connor et al. 2004, Madden \& Grossman 2004, Madden et al. 2005,
2009, Heap \& Harris 2008). Examples include seamounts, fjords, canyons and lagoons (Table 2). Their occurrence can be identified from coastline shape and bathymetric data. It is also possible to define water column (pelagic) seascapes by their hydrographic features, including fronts, pycnoclines, salinity, oxygen concentration and temperature characteristics; as done in Australia's National Marine Bioregionalisation (Commonwealth of Australia 2005). Madden \& Grossman (2004) referred to these as regimes, systems and hydroforms, although the more recent version of this classification has dropped the term regimes (Madden et al. 2009).

A particular seascape may occur in all or a few of the global marine regions, and thus no simple (unidirectional) hierarchical relationship can be applied. Because seascapes are defined using physical features, they are distinct from regions (defined by a mix of geographic, biological and/or political boundaries) and biotopes. A separate classification and dictionary of seascapes is thus necessary. 
Biotopes

The separation of benthic marine habitats by vertical zonation, substrata and, for rocky seashores by wave exposure, have been established in the scientific literature for over $100 \mathrm{yr}$. The lowest levels of a benthic marine, or pelagic, classification would thus be a distinct group of species known to occur under specified environmental conditions in different places. It does not need to be stable in time, and may change with, for example, season, succession or climate change. The middle levels of a hierarchy may be arranged in different ways.

At a regional level, standards based systems for the classification of benthic and pelagic habitats have been developed. The most established is the Marine Nature Conservation Review (MNCR) BioMar classification for seabed habitats and biotopes developed using both data from Britain and Ireland, and expert opinion from throughout Europe (Costello 1995, Hiscock 1995, Connor et al. 1997a,b, 2004, Costello \& Emblow 2005). Building on further data and consultation with experts, this has now been applied to the Northeast Atlantic, Mediterranean, deep sea and pelagic ocean as part of the European Nature Information System (EUNIS, http://eunis.eea.europa.eu). It has a well-developed user manual detailing how to conduct field sampling, identify and map each level in the classification and describe new biotopes (Connor et al. 2004). The upper levels of this habitat classification are physically defined (based on depth, substratum and wave exposure) and thus applicable on a global scale. The lower levels are biotopes that will vary geographically as do species distributions, but the principles and framework of the classification can be applied globally. For example, benthic biotopes have been mapped in British Columbia (Zacharias et al. 1999) and Australia (Butler et al. 2001) using a similar process to the BioMar project. Madden et al. $(2005,2009)$ provided a classification of regions and seascapes for North America, and envisage its lower levels will include habitats and biotopes in a similar manner.

The process of describing, classifying and identifying biotopes can be compared to a species phylogeny. A set of characteristics, in this case the dominant species and physical environment, are used to describe and identify the biotopes and place them in a hierarchical classification structure. Thus the existing habitat classifications hierarchies do not reflect biological relationships or ecological succession. New biotopes will continue to be described as ecological surveys continue, and can be inserted in existing classifications. As in species taxonomy, the most informative operational unit for research and management is the lowest, namely the biotope.
Biotopes are part of habitats in the strict sense in that they are defined by the species present. Although a biotope was first defined as the part of an ecosystem in which a community of species (i.e. a biocoenosis or species association) lived, and has been thus used in oceanographic (e.g. Van der Spoel 1994, Semina 1997, Vinogradov 1997) and freshwater (Padmore 1998) studies, it is now more widely used to include both this habitat and the biocoenosis (Olenin \& Ducrotoy 2006). Benthic biotopes are synonymous with facies. It is used here because the term habitat has been so widely used that it may also refer to regions and seascapes, and sometimes is used interchangeably with the term biotope. Thus for clarity here the term habitat refers to the physical environment in which a species lives, whether physical or biogenic in form (e.g. coral reef).

In Europe, EUNIS is the most likely classification to be used because it is a formal part of the regulatory system used for selecting conservation areas and conducting environmental assessments. In addition, it has the most integrated and ecologically relevant methodology of available systems (e.g. Connor et al. 2004), and has been steadily expanded to other geographic and ocean regions over the years. However, users should remember that this classification hierarchy is designed for administrative purposes rather than scientific research, such that similar levels in the hierarchy are not always ecologically equivalent, as species may be in a taxonomic hierarchy. The directly related classification described by Connor et al. (2004) provides a more balanced hierarchy for benthic habitats, and is available from www.jncc.gov.uk/MarineHabitatClassification. It should be noted that phytoplankton and zooplankton data indicate relatively few pelagic water column biotopes in terms of species composition (Semina 1997, Vinogradov 1997), indicating that these may be aligned with open water seascapes.

\section{Guilds}

Marine animals and plants are commonly grouped according to where they live, their diet, body size and habit, largely reflecting the sampling methods used and subdisciplines in ecology (Table 3). For example, in the water column there are pico-, phyto-, zoo-, mero- and holo-plankton, neuston and nekton (Lincoln et al. 1998). On the seabed there are mega-, macro-, meio-, epi- and infauna, as well as microphytobenthos and epibiota. Demersal (benthopelagic or hyperbenthic) species occur near the seabed, and parasites use other species as habitats. Major groups of organisms can be related to these concepts, and most species can be classified into these categories. Clearly these are useful concepts in ecology and help determine 
whether data sets are comparable for analysis or management. Current benthic classifications are limited to particular guilds; for example, the MNCR BioMar classification was based on visually conspicuous (by diver or video) species and analysis of macrobenthos collected by grabs, cores or dredges.

\section{Approaches to classifications}

The marine environment has been classified in different ways depending on user requirements and resources. These include political, geographic, latitudelongitude, depth, biogeographic regions, seascapes, habitats and biotopes. Approaches have been led by geophysical structure (Greene et al. 1999, Valentine et al. 2005), oceanographic and biological processes (Zacharias \& Roff 2000), species-habitat relationships (Connor et al. 2004, Butler et al. 2001, Zacharias et al. 1999) and their combinations (Madden et al. 2005, 2009). Habitat classifications are the most accurate and ecologically relevant at the biotope level because of the direct relationship between the biota and their environment. This usually requires in situ field data. In contrast, classifications of the environment derived from remotely sensed satellite and aerial images decrease in accuracy as habitat complexity increases (Andrefouet et al. 2003, Capolsini et al. 2003).

Classifications have been developed for freshwater systems in a similar way to marine: first defining habitats by their physical environment and then their associated fauna and flora (e.g. Hawkins et al. 1993, Padmore 1998, Strayer et al. 2006). In contrast, terrestrial classifications have been primarily based on classification of plant communities (Devillers et al. 1991, Olson et al. 2001). On land, plant communities can be a good surrogate for biodiversity (e.g. Blake et al. 2003) because they reflect climate, soil and hydrology condi- tions, and most animals are directly or indirectly dependent on them for habitat and/or food. They are also amenable to mapping by remote sensing. This approach is not possible in the marine environment because plants only occupy shallow waters and, while phytoplankton chlorophyll can be mapped from satellites, its species composition cannot (Platt \& Sathyendranath 2008). In the sea, 3-dimensional habitat structure is provided by geology, hydrology, seaweeds and a wide range of animal taxa from sponges to tubeworms and corals, and is used in defining habitats. However, these species are dependent on the underlying substratum, so it is more appropriate for marine classifications to be based on the physical environment, whether geological or biological in origin.

\section{Geophysical}

Classifications of offshore seabed habitats have produced maps based on topographic features at a range of spatial scales. Greene et al. (1999) distinguished megahabitats (seascapes), mesohabitats, smaller seascapes and macrohabitats (e.g. boulders, caves, biogenic habitats) and microhabitats (seabed material, crevices and relief, individual sessile animals) (Table 4). The term microhabitat is widely used in ecology to refer to habitats that are small in area, typically on a scale of centimetres or millimetres. Strictly speaking, habitats lack a maximum area and some may be larger or smaller than indicated on this scale. Nevertheless, both field survey methods and maps need such a scaling system. Valentine et al. (2005) proposed a set of basic parameters, largely geophysical, on which to build a habitat classification. These are encompassed in the biotope classification of Connor et al. (2004), and both were designed to provide a structured vocabulary for use in data management.

Table 3. Groups of marine species may be classified ecologically as guilds based on their body size, environment, diet and habit. The body size prefixes have been applied to fauna, flora, biota, plankton and benthos; in practice they refer to the mesh size of the net or sieve used to capture them

\footnotetext{
Body size

Pico-; nano-; micro-; meio- or meso-; macro-; mega-

\section{Environment}

Pleuston; neuston; plankton; nekton; phyto-, zooplankton; demersal (hyperbenthos, benthopelagic); benthos; epifauna, flora, biota, epipelic; infauna, endopelic; interstitial

Diet

Predator; scavenger; omnivore; herbivore; parasite; plant (photoautotroph); grazer; suspension feeder; filter feeder; deposit feeder; detritovore; decomposer

Habit

Sessile; sedentary; tubicolous; burrowing; drifting; solitary; gregarious; colonial; encrusting; inquiline; sybiotic; mobile (vagile); chemoautotroph
} 


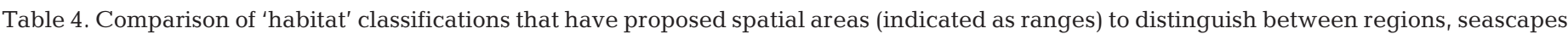

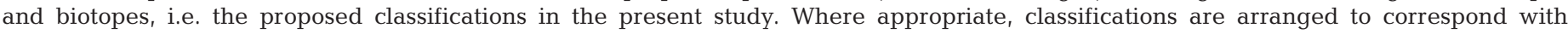
classifications above them in the table. $\mathrm{CEC}=$ Commission for Environmental Cooperation

\begin{tabular}{|c|c|c|c|c|c|c|c|c|}
\hline \multirow{2}{*}{$\begin{array}{l}\text { Source } \\
\text { Greene et al. } \\
\text { (1999) }\end{array}$} & \multirow[t]{2}{*}{ Regions } & \multicolumn{4}{|c|}{$\begin{array}{l}\text { Seascape }- \\
\text { (benthic and pelagic) }\end{array}$} & \multicolumn{3}{|c|}{ Biotope -} \\
\hline & & $\begin{array}{l}\text { Megahabitat } \\
(1-10 \mathrm{~s} \mathrm{~km})\end{array}$ & $\begin{array}{l}\text { Mesohabitat } \\
(10-1000 \mathrm{~m})\end{array}$ & $\begin{array}{l}\text { Macrohabitat } \\
\qquad(1-10 \mathrm{~m})\end{array}$ & $\begin{array}{l}\text { Microhabitat } \\
\quad(<1 \mathrm{~m})\end{array}$ & & & \\
\hline $\begin{array}{l}\text { Zacharias et al. } \\
(1998,1999)\end{array}$ & $\begin{array}{c}\text { Ecozones } \\
\text { Ecoprovinces, } \\
\text { Ecoregions }\end{array}$ & Ecosections & & & & Ecoun & hits = biotope & \\
\hline $\begin{array}{l}\text { Madden et al. } \\
\text { (2005) }\end{array}$ & $\begin{array}{c}\text { Regimes } \\
\left(10->1000 \mathrm{~km}^{2}\right)\end{array}$ & $\begin{array}{l}\text { Formations } \\
\left(0.01-10 \mathrm{~km}^{2}\right)\end{array}$ & $\begin{array}{c}\text { Zone } \\
\left(100-10000 \mathrm{~m}^{2}\right)\end{array}$ & & & $\begin{array}{l}\text { Macrohabitat } \\
\left(100-1000 \mathrm{~m}^{2}\right)\end{array}$ & $\begin{array}{l}\text { Habitat } \\
\left(1-100 \mathrm{~m}^{2}\right)\end{array}$ & $\begin{array}{c}\text { Biotope } \\
\left(1-100 \mathrm{~m}^{2}\right)\end{array}$ \\
\hline $\begin{array}{l}\text { Madden et al. } \\
(2009)\end{array}$ & $\begin{array}{c}\text { CEC } \\
\text { Ecoregions }^{\mathrm{a}}\end{array}$ & $\begin{array}{l}\text { Physiographic } \\
\text { province }\end{array}$ & $\begin{array}{c}\text { Geoform, } \\
\text { Anthropogenic } \\
\text { geoform, Hydroform, } \\
\text { Depth zones (benthic } \\
\text { and in water column) }\end{array}$ & & & $\begin{array}{l}\text { Class and sub- } \\
\text { class of 'Surface } \\
\text { Geology' and } \\
\text { 'Biotic Cover' } \\
\text { components }\end{array}$ & $\begin{array}{l}\text { Biotic } \\
\text { group }\end{array}$ & Biotope \\
\hline
\end{tabular}

One of the most important variables in determining species habitat is substratum, but as yet, this data lies scattered in different marine charts, ecological publications and unpublished data sets, and sampling of the ocean is very variable. Benthic ecologists routinely collect seabed substratum data in conjunction with data on those species which may complement the geological surveys. Often only sediment data is available from grab and core samples with larger rocky and biogenic reef habitats overlooked unless photographic surveys are conducted. However, an initiative is underway that is integrating data sets globally (Jenkins 2008). This project, dbSeabed, uses both numerical data on sediments and word-based descriptors (e.g. shell, seagrass) and will benefit ecologists interested in habitat mapping.

\section{Processes}

The Longhurst (1998) pelagic areas were defined based on measures of ecosystem processes, including phytoplankton biomass and productivity. Comparison of these pelagic areas with benthic species data may reveal that the latter data correspond to Longhurst's (1998) areas. Zacharias \& Roff (2000) proposed a classification using ecological and biological processes at the population (e.g. dispersal, migration, recruitment, evolution, reproduction and indicator species), community (e.g. predation, disease, endemism, biomass and diversity) and ecosystem (e.g. productivity, biogeochemical cycles, retention, anomalies and desiccation) levels. Because all of these processes occur to some extent in most ecosystems, their use in a classification would require quantification. While important biologi- cally and ecologically, their dynamic nature would make them more costly to measure and map than the physical and biological data proposed in most classifications. Instead, defining areas as Longhurst (1998) has done over which these processes vary can be useful in linking biological productivity to environmental conditions. How these ecosystem processes relate to species' biogeographies is not clear.

\section{Biogeography}

There has been no analysis of biogeographic patterns across all taxa for any region, nor for the pelagic and benthic environments at global scales (Eckman 1953, Briggs 1974), although various components have recently been reviewed (e.g. Semina 1997, Vinogradov 1997, Vinogradova 1997, Zezina 1997, UNESCO 2009). Present patterns proposed are compromised by (1) insufficient taxonomic understanding, where widespread species have later been found to be several species; (2) contrasting maps for different taxa; and (3) maps showing species locations without indicating where they have been sampled for and not found (Longhurst 1998). These patterns may vary with depth, so marine biogeography should be considered to have 3-dimensions. In the case of mobile species, such as some large fish and mammals that travel across entire oceans and vertically migrating plankton, their biogeography will change with time, a fourth dimension. The big opportunity and challenge for marine biogeography is to utilise the online databases to map species distributions in both space and time. These databases will contain errors in their source data sets and in data transmission related both to species iden- 
tity and geographic location. The ultimate test of their quality will be their use, such that errors can be corrected and the limitations of particular data can be recognised. As it is unlikely that all the source data sets will be corrected, it is likely that derived products from such megadatabases will be produced, generating new resources for research and management. For example, species range maps are already being produced by matching known species distributions against environmental data (Kaschner et al. 2008).

Biogeographic studies typically use species distribution ranges rather than recorded locations because sampling usually has significant geographic bias. Thus a species range provides a truer picture of where a species may occur. A study may use a species' latitudinal limits or assume it occurs within a wider geographic area (e.g. Mediterranean). Species range maps may be produced by enveloping the recorded locations, and improved by using environmental and habitat data to predict suitable geographic locations, socalled environmental niche mapping (Costello \& Vanden Berghe 2006). Several approaches using online and desktop software facilitate this (e.g. Guinotte et al. 2006, Kaschner et al. 2008). An extension of this approach would predict species ranges under future climate change scenarios. However, within a species' range, an individual will only occur in suitable habitats and where it has a healthy population. Thus biogeographic studies will benefit from habitat information both in predicting species ranges and, at a more local scale, in where species will occur within their range.

\section{Spatial scale}

A distinction has been made about the spatial scale of habitat for nekton, plankton and benthos, and regions, seascapes and biotopes (Table 4). One or more regions may be habitats for migratory mammals, birds, turtles and fish, while seascapes may be an appropriate scale for others. Seascape terrains have been correlated with fish species distribution and richness in coral reefs (Iampietro et al. 2008, Kracker et al. 2008), although these results may be biased by fishing (Wedding \& Friedlander 2008). Current interpretation of oceanographic data suggests there may be only 3 or 4 biogeographic regions and that, combined with vertical zonation, these may be equivalent to pelagic biotopes. The movement of ocean currents horizontally and vertically, wide dispersal of pelagic nekton, vertical migration of zooplankton and widespread plankton expatriation contrasts with the spatial resolution of benthic biotopes at scales of a few metres.

Regions, seascapes and biotopes are in principle without a minimum and maximum size. Lough Hyne, a
$1 \mathrm{~km}^{2}$ sea inlet in southwest Ireland, has been referred to as a giant rock-pool because it has a tidal rapids, a deep basin and is sheltered from wave action. Also like rock pools, coastal lagoons can be permanent or seasonal, and range from freshwater ponds to those with euryhaline or hypersaline conditions (Barnes 1994). The Baltic Sea could be considered a giant estuary, ranging from full freshwater to full salinity. Seascapes typically have multiple biotopes within them, varying in substratum, depth (light) and wave and current exposure. But, like landscapes, it is common usage that they will be 100 s to 1000 s of square metres in area. However, at some point a decision is required as to when to delimit their area. The MNCR BioMar project used $5 \mathrm{~m}^{2}$ as its minimum area for field recording of biotopes (Connor et al. 1997a, b). Other classifications address habitats from scales of $>1000 \mathrm{~km}^{2}$ to $1 \mathrm{~m}^{2}$ (Table 4). Zacharias et al. (1998) proposed a classification of areas based on their areal extent, namely ecozones (e.g. Pacific Ocean), ecoprovinces (continental margins, e.g. Pacific north-east), ecoregions (marginal seas), ecosections (coastal seascapes) and ecounits (biotopes). The size of these areas has not been correlated to, or distinguished by, either species distributions or ecosystem processes data. Data users can apply area-based classifications as their needs require, so it may not be necessary to categorise data in this way a priori.

\section{Classification hierarchies}

Habitat classifications imply or provide definitions of words used and show their relationships. It helps if these are hierarchical because one can then map habitats at different levels depending on the scale and size of the map, end-user needs and available data. Importantly, it also means that, like a classification of species, lower levels can be aggregated into higher levels. In reality, classification hierarchies are multidimensional but they are forced into linear lists for presentation purposes. Pelagic and benthic habitats are usually classified separately because their environments and species are so distinctive (e.g. Southern 1915, Roff \& Taylor 2000). Matrices provide a more natural, but still 2-dimensional, relationship between biotopes (Connor et al. 1997a,b, Costello \& Emblow 2005), and were used by Pruvot in 1897 to illustrate intertidal and subtidal biotopes (cited in Southern 1915). Such frameworks can be useful in identifying gaps in sampling and the occurrence of habitats in a study area. Some habitats in such a framework may not exist, such as wave-exposed habitats in the deep sea.

The exchange of marine habitat data would be facilitated if the (word or code used to) name of a habitat 
automatically and unambiguously informed the database as to its position in the hierarchy. This is analogous to being able to tell from a species name what family, order, class and phylum it belongs to. However, this does not mean a single hierarchical classification. Users could create their own classification according to their needs by linking regions, seascapes and biotopes. For example, one user may wish to classify by country/ estuary/littoral/mudflats/Corophium community, and another a Longhurst area/deep-water coral reef.

Levels in a hierarchy may reflect conservation priorities, the history of the classification and/or available scientific information; others may place similar concepts at the same level as in taxonomic phylogenies. For example, the MNCR BioMar classification (Connor et al. $1997 a, b)$ first classified biotopes by the physical conditions that were most important in separating them (e.g. substratum, then wave exposure); this classification is now nested within EUNIS whose levels represent its development as a nature conservation tool.

\section{DATA MANAGEMENT ISSUES}

\section{Interoperability}

The arrival of software that enables interoperability between databases provides new opportunities to publish and thus share data between researchers and endusers located in different cities and countries. However, data interoperability requires standardised fields that form a data schema that is the basis of the middleware that connects different databases. Already, the publication of geographic, taxonomic and time of collection data on marine species is underway through GBIF and related initiatives. However, many users are only interested in particular habitats, such as coral reefs, seagrass beds, seashores, estuaries or seamounts. Others may want to know where certain habitats occur or how much of a habitat exists in an area. To provide ecological context to marine species distribution data, these online databases need to develop a system for exchanging data on marine habitats. The present overlays of global bathymetry, sea surface temperature, salinity and other environmental data have a role in mapping marine habitats. However, ground-truth data associated with the species being mapped will provide the greatest accuracy. Another approach may be to relate species or higher taxonomic groups to one or more habitats. This will need some research to deal with different habitats for adults and larvae, how to deal with species that are exceptions within their genus or family, and perhaps other factors. The requirements of a global marine habitat classification are to (1) facilitate data and information exchange and interoperability; (2) be relevant to end-users, including those in conservation, fisheries, research and education; (3) include a comprehensive glossary of terminology; (4) use simpler terms and minimise jargon; (5) be consistent with existing use of terminology in marine ecology; (6) relate to existing marine habitat classifications; (7) enable capture of marine habitat information from existing data sources; and (8) enable capture of marine habitat information from new data sources.

While there may be few databases that already have matched species and/or geographic locations to a standard habitat classification at present, many publications have done so. In either instance it will be necessary to translate between terminology to integrate data into larger databases as part of the interoperability process. An automated service that matches species names with their synonyms is available at www. marinespecies.org, and exceptions may be sent to taxonomic editors for inclusion in the database as valid species or new synonyms. A similar system for habitats could be established, such that any unrecognised terms would be noticed and sent to experts for classification. Because a wealth of data and information already use regional classifications, a global-scale classification should build on and/or be able to translate from them. The concepts discussed in this paper provide a basis for such a translator.

\section{Vocabularies}

The growth of large databases, such as GenBank and GBIF, depends upon many small data sets being integrated using standard data schema and exchange protocols. To allow this interoperability, data need to follow defined vocabularies, including understanding of semantic relationships that show how terms are related (e.g. equivalent, or if one is a subset or superset of another). Both research and environmental management benefit from the availability of standardised marine habitat classifications because alternative terminologies will be minimised, dictionaries (or glossaries) of terms become available and relationships between concepts apparent. This simpler and better definition of words used to describe and label marine habitats should improve communication between scientists and end-users, and reduce alternative uses of words. However, knowledge of other uses of words is necessary to interpret the scientific literature. For example, the term littoral in marine ecology normally applies to the intertidal or seashore, but it has also been used to mean the coastal land and continental shelf (Aquatic Sciences and Fisheries Abstracts [ASFA] 2009). Thus, to develop the semantic web, where relationships between words are understood by comput- 
ers, terminology would need to mapped into ontologies. The Marine Metadata Interoperability initiative (MMI 2009) aims to develop such resources.

A useful online glossary of terminology that cites the sources for each definition is available from the Marine Life Information Network (MarLIN 2009), the ASFA thesaurus (2009) provides relationships between terminology, and seascapes have been defined by the International Hydrographic Organization (IHO 2008) and Heap \& Harris (2008). Such resources provide the basis for an online dictionary of terminology. Being online it could grow in time and include alternative definitions. It could include definitions proposed by experts in marine ecology exposed to peer review and subsequently endorsed by a panel of experts. Such a dictionary should be a priority for a data exchange system because it will allow future translation between terminologies and cross-mapping between classifications.

Shortened versions of the descriptive titles of habitats and biotopes are useful in data management and labelling of maps. Such coding systems have been reported in several studies (e.g. Valentine et al. 2005). Connor et al. (1997a,b, 2004) provide a hierarchical, human readable, letter code for biotopes that can be directly related to the numerical administrative codes used in EUNIS. Madden et al. (2009) proposed a similar letter code for North American biotopes.

\section{Role of primary data and metrics}

For data management, it is preferable to record the basic features of biotopes, such as seabed relief and sediment, depth and the dominant fauna and flora, especially the density of those species that may provide habitat structure for other species (e.g. coral reefs, shellfish and seagrass beds, kelp and mangrove forests) (Tables $4 \& 5$ ). Where parameters can be quantified, through measurement (e.g. depth, temperature) or some semi-quantitative scale (e.g. wave exposure), these data should be recorded to enable more accurate classification of habitats.

Where a well-established biotope classification exists it may be directly applied to sample data. Thus data schema standards may be expanded to include dictionaries and codes for biotopes so users can search for data on particular biotopes. In addition, it may be possible to identify biotopes from the presence of characteristic species. For example, some species only occur on the littoral fringe of wave-exposed rocky seashores, along the strandline of beaches or associated with chemosynthetic ecosystems. By entering the primary parameters from which classifications can be derived into a database, it should be possible for users to then classify habitats for their particular need.

Table 5. Examples of the parameters that could be recorded to aid habitat classification in data management systems. ${ }^{*}$ : some parameters may be inferred from observations rather than measured

\author{
Environment \\ Location \\ Depth below surface \\ Light penetration (e.g. as illumination, secchi depth, turbidity) \\ Temperature \\ Wave fetch \\ Current and tidal velocity \\ Substratum material (e.g. \% composition of silt, mud, sand, gravel, cobble, shell, boulder, bedrock) \\ Substratum stability* \\ Scour (e.g. current, ice) \\ Topography (see Table 2) \\ Rock relief (e.g. roughness, crevices, fissures, fractures, faults, folds) \\ Sediment relief (e.g. ripples, sand-waves, hummocks, mounds) \\ Slope (e.g. flat, vertical, overhang \\ Biogenic structures (e.g. burrows, hollows, excavations, tubes, shell-beds, reefs, turf) \\ Biogenic habitat (e.g. mussel or oyster bed, coral, tubeworm or bryozoan reef, maerl (rhodolith), seaweed, seagrass, other \\ epifauna) \\ Salinity (e.g. euhaline, hypersaline, oligohaline, polyhaline, euryhaline) \\ Oxygen saturation in water (e.g. supersaturated, hypoxia, anoxia); in sediment as redox potential and depth of oxidised layer \\ Anthropogenic (e.g. debris, shipwreck, trawl tracks, fishing gear, coastal structure, ropes) \\ Ice cover and margin (whether permanent or seasonal) \\ Tidal range or amplitude \\ Biota \\ Dominant species (\% cover or density) \\ Sampling method (observation, grab, net, etc.) \\ Biological scope of sampling (e.g. macrobenthos, meiofauna, neuston, zooplankton) \\ Habit or growth form (e.g. burrowing, erect, cushion, encrusting, mat, film, filamentous, turf, sward, foliose, forest, reef)
}




\section{EXISTING CLASSIFICATIONS}

Marine habitat classifications have been developed from regional to local scales to aid the selection of conservation areas in France (Dauvin 1993, 1994), Britain and Ireland (Connor et al. 1997a,b), Canada (Zacharias \& Howes 1998, Day \& Roff 2000, Roff \& Taylor 2000), Australia (IMCRA Technical Group 1998, Commonwealth of Australia 2005, 2006) and the USA (Madden et al. 2009). They are increasingly in demand for the mapping and reporting of biodiversity by government and non-governmental organisations. Organisations such as the European Environment Agency (EEA), International Union for Conservation of Nature (IUCN), International Council for the Exploration of the Sea (ICES) and Food and Agriculture Organisation (FAO) have developed classifications from regional to global scales by summarising data in ecologically relevant areas defined by geography or environment, and/or areas considered practical for management purposes. Marine environmental data within New Zealand's EEZ have been compared with biological data to map ecologically relevant environmental areas that can be used in conservation planning (Leathwick et al. 2004). A continental scale classification is operational in Europe, and others are being developed in North America, South America, Australia and New Zealand by NOAA, NatureServe, the Inter-American Biodiversity Information Network and Australian and New Zealand government agencies. The need for global marine habitat classifications for data management has been recognised by GEOSS, OBIS, UNESCO, UNEP (United Nations Environment Programme), FAO, the Intergovernmental Oceanographic Commission and the Convention on Biological Diversity; and for conservation management by WWF, IUCN, the Wildlife Conservation Society, The Nature Conservancy, NatureServe and the Ramsar Convention.

In terms of classifications of global regions, users can select which best suits their needs or their audience. At a global level, GIS-compatible digital maps are now available for political and geographic regions based on international standards, namely the EEZ and IHO (1953) seas and oceans. The ocean may also be classified by latitude-longitude boxes (the size depending on the users need) and by depth. These political, geographic and spatially defined systems are widely understood, standards-based, and probably the most widely used in descriptions of where species occur. Their combination may well define larger regions which are useful for management. For conservation planning and reporting the MEOW and GOODS systems may be preferred, and for fisheries the FAO, Longhurst or ICES areas. Shapefiles of the EEZ, IHO, LME, Longhurst areas or FAO regions are download- able at www.vliz.be/vmdcdata/vlimar/downloads.php and ICES, upon request.

GEO is developing a standardised classification of terrestrial ecosystems based on climate, land topography, soil and land-cover data. Thus the regions mapped will be objectively defined by the same metrics, facilitating updating as improved data become available and providing a standard approach to collecting in situ data and regional planning. A similar approach could be conducted using ocean climate in 3-dimensions (i.e. water mass), seascapes from bathymetry, and substratum data. However, as previously discussed, the latter is lacking for most of the ocean at present, and the former require analytical effort.

Global bathymetric maps have been prepared using combinations of soundings and gravitational anomalies measured from satellites (Smith \& Sandwell 1997, Becker 2008, Becker et al. 2009). The accuracy of these maps decreases with increasing resolution, but they should be adequate for defining seascape features larger than about $10 \mathrm{~km}$. This will require clear definition of the seascapes in terms of depth, shape and slope at particular spatial resolutions; an issue recently raised in the proceedings of a symposium on marine GIS (Wright \& Heyman 2008). Similarly, analyses of environmental and pelagic species distribution data are required to establish the occurrence of pelagic seascapes and biotopes. It may be found that these are synchronous.

Drop-down menus can be provided in a database and website portal for predetermined regions, seascapes and biotopes (Table 2) and guilds (Table 3). Examples of such options for Longhurst, FAO, ICES, IHO Oceans and Seas, EEZ and LME have been available from a drop-down menu on OBIS for several years (Costello et al. 2007). Similar searchable maps could be provided for any selection of shapefiles, such as MEOW or GOODS regions, or seascapes.

\section{CONCLUSIONS}

Because they are sampled (and thus defined) by different methods and can operate at different spatial scales, separate classifications are recommended for (1) nekton, plankton and benthos, and (2) regions, seascapes, biotopes and guilds. Furthermore, it is recommended to avoid imposing a hierarchical classification where the concepts and methods of defining them are different. The same biotopes may occur in multiple seascapes, and seascapes in multiple regions, while the same seascapes may have different suites of biotopes. Another way of testing the classification hierarchy is to judge how the lower levels help predict the upper levels. A species can predict the presence of a 
habitat, and perhaps a biogeographic region. However, a habitat will not necessarily predict a seascape, nor a seascape a region. Classifying regions, seascapes and biotopes separately is thus simpler for data management, and users can combine the concepts where appropriate for their purposes and thus create their own hierarchies.

There are several existing habitat classifications that can be used for data exchange and management. Some, here called regions and seascapes, can be presented as maps overlaid on point data. They can be defined as polygons in GIS and remain stable over time. In contrast, if biogeographic boundaries occur in the oceans (as opposed to gradients), then they are likely to move with changes in the ocean climate. Several options for global classification of regions are now available. However, standardised digital maps of seascapes remain to be published.

There is consensus that biotopes are the lowest level of marine habitat classifications. Habitats sensu strictu and biotopes are best linked to individual species data records because they are defined by the species present in a particular physical environment. Because of their ecology and changing environmental conditions, the extent and distribution of biotopes can change over time. Thus it may be best to generate biotope maps using carefully selected data (e.g. collected in a short time period) for particular uses. These biotope maps can become a valuable baseline in studies on the ecosystem effects of fishing and environmental change. Species characteristics used to define guilds (e.g. macrobenthos, plankton) can be used to classify data sets suitable for comparative analysis.

While the practical framework for a biotope classification is established, biotope inventories have only begun to be developed in Europe (EUNIS, Connor et al. 2004), parts of Canada (Zacharias et al. 1999), Australia (Butler et al. 2001, Commonwealth of Australia 2005, 2006) and the USA (Madden et al. 2009). While classifications of the pelagic environment exist, pelagic seascapes and biotopes remain to be characterised.

The publication of millions of locations of thousands of species in online databases provides new opportunities for analyses to derive maps of marine biogeographic regions. Including ecological classifications will enable analyses that relate species phylogenies to ecological adaptations and ecosystem function. However, to achieve this at a global scale will require ecologists to be clear on what concepts they are classifying and why, and to build on the 2 centuries of experience in marine habitat classification rather than inventing new terminologies that may serve to confuse their audience. An online peerreviewed glossary of recommended terminology will help minimise alternative uses of terms and provide a vocabulary for data management.
The purpose of terms like habitats, ecosystems, biodiversity, ecotones and biotopes is to communicate important concepts. The clarification of these concepts for data management will reduce semantic confusion and increase positive feedback to benefit environmental management, research and education.

Acknowledgements. This study was part-funded by grant no. 612 from the Gordon and Betty Moore Foundation to Karen Stocks and colleagues at the University of California, San Diego, and Alfred P. Sloan Foundation to the Census of Marine Life's OBIS through Rutgers - the State University of New Jersey. The study benefited from helpful discussion with A. Cheung, D. Connor, F. Grassle, A. Gupta, K. Stocks, D. Grossman, C. Madden, C. Rose-Taylor, Y. Zhang, and the many people involved in workshops on marine habitat classifications in Europe, Canada and USA. I especially thank A. Butler, K. Goodin and anonymous referees for helpful comments on this paper. This is MarBEF publication no. MPS09036.

\section{LITERATURE CITED}

Andrefouet S, Kramer P, Torres-Pulliza D, Joyce KE and others (2003) Multi-sites evaluation of IKONOS data for classification of tropical coral reef environments. Remote Sens Environ 88:128-143

Andrefouet S, Gilbert A, Yan L, Remoissenet G, Payri C, Chancerelle Y (2005) The remarkable population size of the endangered clam Tridacna maxima assessed in Fangatau Atoll (Eastern Tuamotu, French Polynesia) using in situ and remote sensing data. ICES J Mar Sci 62: $1037-1048$

Andrefouet S, Costello MJ, Faith DP, Ferrier S and others (2008) The GEO Biodiversity Observation Network Concept Document. Group on Earth Observations, Geneva

Aquatic Sciences and Fisheries Abstracts (2009) ASFA thesaurus. Available at http://www4.fao.org/asfa/asfa.htm

Barnes RSK (1994) The coastal lagoons of Europe. Coastline $3: 3-8$

Becker JJ (2008) Improved global bathymetry, global sea floor roughness, and deep ocean mixing. $\mathrm{PhD}$ thesis, University of California, San Diego, CA

Becker JJ, Sandwell DT, Smith WHF, Braud J and others (in press) (2009) Global bathymetry and elevation data at 30 arc seconds resolution: SRTM30_PLUS. Mar Geod

> Benson J (2008) Classifying ecological communities and synthesizing data for natural resource management: some problems and potential solutions. Ecol Manag Restor 9: $86-87$

Best BD, Halpin PN, Fujioka E, Read AJ, Qian SS, Hazen LJ, Schick RS (2007) Geospatial web services within a scientific workflow: predicting marine mammal habitats in a dynamic environment. Ecol Inform 2:210-223

Blake S, McCracken DI, Eyre MD, Garside A, Foster GN (2003) The relationship between the classification of Scottish ground beetle assemblages (Coleoptera, Carabidae) and the National Vegetation Classification of British plant communities. Ecography 26:602-616

Briggs JC (1974) Marine zoogeography. McGraw-Hill, New York

Butler A, Harris P, Lyne V, Heap A, Passlow V, Smith R (2001) An interim, draft bioregionalisation for the continental slope and deeper waters of the south-east marine region of 
Australia. CSIRO and National Oceans Office, Hobart

Capolsini P, Andrefouet S, Rion C, Payri C (2003) A comparison of Landsat ETMC, SPOT HRV, IKONOS, ASTER and airborne MASTER data for coral reef habitat mapping in South Pacific islands. Can J Remote Sens 29:187-200

Cattrijsse A, Hampel H (2006) European intertidal marshes: a review of their habitat functioning and value for aquatic organisms. Mar Ecol Prog Ser 324:293-307

Commonwealth of Australia (2005) National marine bioregionalisation of Australia. Department of the Environment and Heritage, Canberra

Commonwealth of Australia (2006) A guide to the integrated marine and coastal regionalisation of Australia, version 4.0. Department of the Environment and Heritage, Canberra

Connor DW, Brazier DP, Hill TO, Northen KO (1997a) Marine nature conservation review: marine biotope classification for Britain and Ireland, Vol. 1. Littoral biotopes. Report No. 229, Joint Nature Conservation Committee, Peterborough

Connor DW, Dalkin MJ, Hill TO, Holt RHF, Sanderson WG (1997b) Marine nature conservation review: marine biotope classification for Britain and Ireland, Vol. 2. Sublittoral biotopes. Report No. 230, Joint Nature Conservation Committee, Peterborough

Connor DW, Allen JH, Golding N, Howell KL, Lieberknecht LM, Northen KO, Reker JB (2004) The marine habitat classification for Britain and Ireland. Version 04.05. Joint Nature Conservation Committee, Peterborough, available at www.jncc.gov.uk/MarineHabitatClassification

Connor DW, Gilliland PM, Golding N, Robinson P, Todd D, Verling E (2006) UKSeaMap: the mapping of seabed and water column features of UK seas. Joint Nature Conservation Committee, Peterborough

Costello MJ (1992) Abundance and spatial overlap of gobies in Lough Hyne, Ireland. Environ Biol Fishes 33:239-248

Costello MJ (1995) The BioMar (Life) project: developing a system for the collection, storage, and dissemination of marine data for coastal management. In: Hiscock K (ed) Classification of benthic marine biotopes of the north-east Atlantic. Joint Nature Conservation Committee, Peterborough, p 9-17

Costello MJ (2001) To know, research, manage, and conserve marine biodiversity. Oceanis 24:25-49

Costello MJ (2009) Motivation of online data publication. Bioscience 59:418-427

Costello MJ, Emblow C (2005) A classification of inshore marine biotopes. In: Wilson JG (ed) The intertidal ecosystem: the value of Ireland's shores. Royal Irish Academy, Dublin, p 25-35

Costello MJ, Vanden Berghe E (2006) 'Ocean Biodiversity Informatics': a new era in marine biology research and management. Mar Ecol Prog Ser 316:203-214

Costello MJ, Partridge J, Rogers S, Shand J (1990) Habitat and distribution of gobies in Lough Hyne, Ireland. Prog Underwat Sci 15:73-84

Costello MJ, McGrath D, Emblow C (1999) A review of the distribution of marine Talitridae (Amphipoda) in Ireland, including the results of a new survey of sandy beaches. In: Schram FR, von Vaupel Klein JC (eds) Crustaceans and the biodiversity crisis. Proc 4th Int Crustac Congr, Amsterdam, 20-24 Jul 1998. Brill, Leiden, p 473-487

Costello MJ, McCrea M, Freiwald A, Lundalv T and others (2005) Functional role of deep-sea cold-water Lophelia coral reefs as fish habitat in the north-eastern Atlantic. In: Freiwald A, Roberts JM (eds) Cold-water corals and ecosystems. Springer-Verlag, Berlin, p 771-805

Costello MJ, Stocks K, Zhang Y, Grassle JF, Fautin DG (2007)
About the Ocean Biogeographic Information System Available at http://hdl.handle.net/2292/5236

Dauvin JC (1993) Typologie des ZNIEFF-Mer, liste des paramètres et des biocoenoses des côtes françaises métropolitaines. Coll. Patrimoines Naturels, Vol 12. Secrétariat Faune-Flore/MNHN, Paris

Dauvin JC (1994) Typologie des ZNIEFF-Mer, liste des paramètres et des biocoenoses des côtes françaises métropolitaines. Coll. Patrimoines Naturels, Vol 12, 2nd édn. Secrétariat Faune-Flore/MNHN, Paris

Day J, Roff J (2000) Planning for representative marine protected areas. A framework for Canada's oceans. World Wildlife Fund, Toronto

> Degraer S, Moerkerke G, Rabaut M, Van Hoey G and others (2008) Very-high resolution side-scan sonar mapping of biogenic reefs of the tube-worm Lanice conchilega. Remote Sens Environ 112:3323-3328

Devillers P, Devillers-Terschuren J, Ledant JP (1991) CORINE biotopes manual: habitats of the European Community. Commission of the European Communities, Directorate General of Environment, Nuclear Safety and Civil Protection, Luxembourg

> Diaz RJ, Solan M, Valente RM (2004) A review of approaches for classifying benthic habitats and evaluating habitat quality. J Environ Manag 73:165-181

Ekman S (1953) Zoogeography of the sea. Sidgwick \& Jackson, London

Freitas R, Sampaio L, Oliveira J, Rodrigues AM, Quintino V (2006) Validation of soft bottom benthic habitats identified by single-beam acoustics. Mar Pollut Bull 53:72-79

Froese R, Pauly D (eds) (2009) FishBase. Available at www.fishbase.org

Greene HG, Yoklavich MM, Starr RM, O'Connell VM and others (1999) A classification scheme for deep seafloor habitats. Oceanol Acta 22:663-678

Guinotte JM, Bartley JD, Iqbal A, Fautin DG, Buddemeier RW (2006) Modeling habitat distribution from organism occurrences and environmental data: case study using anemonefishes and their sea anemone hosts. Mar Ecol Prog Ser 316:269-283

$>$ Halpin PN, Read AJ, Best BD, Hyrenbach KD and others (2006) OBIS-SEAMAP: developing a biogeographic research data commons for the ecological studies of marine mammals, seabirds, and sea turtles. Mar Ecol Prog Ser 316:239-246

Hawkins CP, Kershner JL, Bisson PA, Bryant MD and others (1993) A hierarchical approach to classifying stream habitat features. Fisheries 18:3-12

Heap AD, Harris PT (2008) Geomorphology of the Australian margin and adjacent seafloor. Aust J Earth Sci 55:555-585

Hiscock K (ed) (1995) Classification of benthic marine biotopes of the north-east Atlantic. Joint Nature Conservation Committee, Peterborough

Iampietro PJ, Young MA, Kvitek RG (2008) Multivariate prediction of rockfish habitat suitability in Cordell Bank National Marine Sanctuary and Del Monte Shalebeds, California, USA. Mar Geod 31:359-371

IMCRA (Interim Marine and Coastal Regionalisation for Australia) Technical Group (1998) Interim Marine and Coastal Regionalisation for Australia: an ecosystem-based classification for marine and coastal environments. Version 3.3. Environment Australia, Commonwealth Department of the Environment, Canberra

IHO (International Hydrographic Organization) (2008) Standardization of undersea feature names. Guidelines, proposal form, terminology. Bathymetric Publication No. 6, International Hydrographic Bureau, Monaco 
IHO (International Hydrographic Organization) (1953) Limits of oceans and seas. Special Publication No. 23, International Hydrographic Bureau, Monaco

Jax K (2006) Ecological units: definitions and application. Q Rev Biol 81:237-258

Jenkins C (2008) dbSEABED: an information processing system for marine substrates. Available at http://instaar. colorado.edu/ jenkinsc/dbseabed/

Kaschner K, Ready JS, Agbayani E, Rius J and others (2008) AquaMaps: predicted range maps for aquatic species. Available at www.aquamaps.org

Kenny AJ, Cato I, Desprez M, Fader G, Schüttenheim RTE, Side J (2003) An overview of seabed-mapping technologies in the context of marine habitat classifications. ICES J Mar Sci 60:411-418

Kracker L, Kendall M, McFall G (2008) Benthic features as a determinant for fish biomass in Gray's Reef National Marine Sanctuary. Mar Geod 31:267-280

Leathwick J, Image $\mathrm{K}$, Snelder T, Weatherhead M, Wild M (2004) Definition and test of marine environment classifications of New Zealand's Exclusive Economic Zone and the Hauraki Gulf. NIWA Client Report CHC2004-085, National Institute of Water and Atmospheric Research, Christchurch

Legendre P, Ellingsen KE, Bjornbom E, Casgrain P (2002) Acoustic method classification: improved statistical method. Can J Fish Aquat Sci 59:1085-1089

Lincoln RJ, Boxshall GA, Clark PF (1998) A dictionary of ecology, evolution and systematic, 2nd edn. Cambridge University Press, Cambridge.

Longhurst A (1998) Ecological geography of the sea. Academic Press, San Diego, CA

Madden CJ, Grossman DH (2004) A framework for a coastal/marine ecological classification standard. NatureServe, Arlington, VA

Madden CJ, Grossman DH, Goodin KL (2005) Coastal and marine systems of North America: framework for an ecological classification standard, Version II. NatureServe, Arlington, VA

Madden CJ, Goodin K, Allee RJ, Cicchetti G, Moses C, Finkbeiner M, Bamford D (2009) Coastal and marine ecological classification standard NOAA and NatureServe. $109 \mathrm{p}$.

MarLIN (2009) MarLIN glossary. The Marine Life Information Network for Britain and Ireland. Available at www. marlin.ac.uk/glossaries/glossary.php

MMI (Marine Metadata Initiative) (2009) Marine metadata interoperability. Available at http://marinemetadata.org/

Mumby PJ, Broad K, Brumbaugh DR, Dahlgren CP and others (2008) Coral reef habitats as surrogates of species, ecological functions, and ecosystem services. Conserv Biol 22:941-951

O'Dor RK, Fennel K, Vanden Berghe E (2009) A one ocean model of biodiversity. Deep-Sea Res II 56:1816-1823

> Olenin S, Ducrotoy JP (2006) The concept of biotope in marine ecology and coastal management. Mar Pollut Bull 53:20-29

Olson DM, Dinerstein E, Wikramanayake ED, Burgess ND and others (2001) Terrestrial ecoregions of the world: a new map of life on earth. Bioscience 51:933-938

Padmore CL (1998) The role of physical biotopes in determining the conservation status and flow requirements of British rivers. Aquat Ecosyst Health Manag 1:25-35

Pauly D (1999) Longhurst areas: ecological geography of the sea by A. Longhurst. Trends Ecol Evol 14:118

Pérès JM, Picard J (1964) Nouveau manuel de bionomie ben- thique de la mer Méditerranée. Bulletin No. 31, Recueil des Travaux de la Station Marine d'Endoume, Aix-enProvence

Platt T, Sathyendranath S (2008) Ecological indicators for the pelagic zone of the ocean from remote sensing. Remote Sens Environ 112:3426-3436

> Redfern JV, Ferguson MC, Becker EA, Hyrenbach KD and others (2006) Techniques for cetacean-habitat modeling. Mar Ecol Prog Ser 310:271-295

Risser PG (1995) The status of the science examining ecotones. Bioscience 45:318-325

Roff JC, Taylor ME (2000) National frameworks for marine conservation - a hierarchical geophysical approach. Aquat Conserv 10:209-223

Semina HJ (1997) An outline of the geographical distribution of oceanic phytoplankton. Adv Mar Biol 32:527-563

Sherman K, Sissenwine M, Christensen V, Duda A and others (2005) A global movement toward an ecosystem approach to management of marine resources. Mar Ecol Prog Ser 300:275-279

Smith WHF, Sandwell DT (1997) Global sea floor topography from satellite altimetry and ship depth soundings. Science 277:1956-1962

Southern R (1915) Clare Island Survey. Marine ecology. Proc R Ir Acad B 31:1-108

Spalding MD, Fox HE, Allen GR, Davidson N and others (2007) Marine ecoregions of the world: a bioregionalization of coastal and shelf areas. Bioscience 57:573-583

Strayer DL, Malcom HM, Bell RE, Carbotte SM, Nitsche FO (2006) Using geophysical information to define benthic habitats in a large river. Freshw Biol 51:25-38

UNESCO (2009) Global Open Oceans and Deep Seabed (GOODS) biogeographic classification. IOC Technical Series 84, UNESCO-IOC, Paris

Valentine PC, Todd BJ, Kostylev VE (2005) Classification of marine sublittoral habitats, with application to the northeastern North America region. Am Fish Soc Symp 41: $183-200$

> van der Spoel S (1994) The basis for boundaries in pelagic biogeography. Prog Oceanogr 34:121-133

- Vinogradov ME (1997) Some problems of vertical distribution of meso- and macroplankton in the ocean. Adv Mar Biol 32:1-92

Vinogradova NG (1997) Zoogeography of the abyssal and hadal zones. Adv Mar Biol 32:325-387

> Wedding LM, Friedlander AM (2008) Determining the influence of seascape structure on coral reef fishes in Hawaii using a geospatial approach. Mar Geod 31:246-266

Wright DJ, Heyman WD (2008) Introduction to the Special Issue: marine and coastal GIS for geomorphology, habitat mapping, and marine reserves. Mar Geod 31:223-230

Zacharias MA, Howes DE (1998) An analysis of marine protected areas in British Columbia, Canada, using a marine ecological classification. Nat Areas J 18:4-13

Zacharias MA, Roff RC (2000) A hierarchical ecological approach to conserving marine biodiversity. Conserv Biol 14:1327-1334

Zacharias MA, Howes DE, Harper JR, Wainwright P (1998) The British Columbia marine ecosystem classification: rationale, development, and verification. Coast Manag 26: 105-124

Zacharias MA, Morris MC, Howes DE (1999) Large scale characterization of intertidal communities using a predictive model. J Exp Mar Biol Ecol 239:223-242

Zezina ON (1997) Biogeography of the bathyal zone. Adv Mar Biol 32:389-426 